JAMP: Jurnal Adminitrasi dan Manajemen Pendidikan

Volume 1 Nomor 3 September 2018, Hal : 279-283

Tersedia Online di http://journal2.um.ac.id/index.php/jamp/

ISSN 2615-8574 (online)

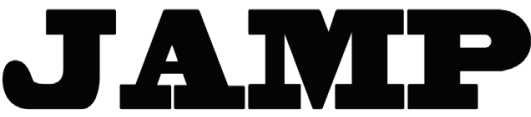

JURNAL ADMINISTRASI DAN MANAJEMEN PENDIDIKAN

\title{
PENGARUH ETIKA PROFESIONAL TERHADAP PEMBENTUKAN KARAKTER MAHASISWA
}

\author{
Sultoni \\ Imam Gunawan \\ Dika Novita Sari \\ imam.gunawan.fip@um.ac.id \\ Universitas Negeri Malang, Jl. Semarang No. 5 Malang 65145
}

\begin{abstract}
The purpose of this research is to determine the influence of professional ethics (X) to student character building (Y). Quantitative methods are used in this study. The research instrument is a questionnaire. Sampling technique using quota random sampling. The sample of research is 73 students Faculty of Education (FIP) State University of Malang (UM) as a participant in Character Building Training. Data analysis used was: descriptive analysis with stanfive formula and simple regression test. The result of this research concluded that there is significant influence of professional ethics variable $(\mathrm{X})$ to student character building $(\mathrm{Y})$.
\end{abstract}

Keywords: professional ethics, student character building

\begin{abstract}
Abstrak: Intensitas komunikasi adalah pertukaran informasi dalam kurun waktu tertentu. PeningkataTujuan penelitian ini adalah untuk mengetahui pengaruh etika profesional (X) terhadap pembentukan karakter mahasiswa (Y). Metode kuantitatif digunakan dalam penelitian ini. Instrumen penelitian ialah angket tertutup. Teknik pengambilan sampel dengan menggunakan quota random sampling. Sampel penelitian adalah 73 orang mahasiswa Fakultas Ilmu Pendidikan (FIP) Universitas Negeri Malang (UM) yang mengikuti pelatihan Character Building. Analisis data yang digunakan adalah: analisis deskriptif dengan formula stanfive dan uji regresi sederhana. Hasil penelitian disimpulkan bahwa ada pengaruh yang signifikan variabel etika profesional $(\mathrm{X})$ terhadap pembentukan karakter mahasiswa (Y).
\end{abstract}

Kata kunci: etika profesional, pembentukan karakter mahasiswa

Etika merupakan suatu kumpulan asas, nilai, atau moral menjadi pedoman seseorang dalam berperilaku. Etika juga berkenaan dengan hal baik dan hal buruk dalam berperilaku yang di dalamnya terdapat hak dan kewajiban moral seseorang dalam hidup bermasyarakat. Etika adalah sistem nilai yang digunakan memutuskan apa yang benar dan dalam suatu situasi tertentu memutuskan apa yang konsisten dengan sistem nilai yang ada dalam individu dan organisasi (Gunawan, 2015; Pertiwi, dkk., 2017). Etika merupakan bagian integral dari semua aktivitas kehidupan manusia dalam banyak hal (Chan, 2018; Miles dan Craddock, 2018). Etika secara universal juga berlaku pada konsep etika profesional. Etika profesional merupakan ukuran tingkah laku yang bersumber dari etika-etika umum dan menjadi pedoman berperilaku dalam bidang profesional tertentu.

Etika profesional merupakan wujud integritas seseorang terhadap organisasi. Greenstone (2018) menyatakan bahwa etika profesional seseorang ditunjukkan dengan: (1) kesadaran seseorang akan aturan yang berlaku dari nilai-nilai yang disepakati; (2) kesediaan seseorang untuk melakukan dialog dengan berbagai entitas yang ada dalam organisasi; dan (3) etika menjadi bahan pertimbangan dalam berinteraksi antara pimpinan dan sesama anggota organisasi. Etika profesional harus dipegang oleh setiap orang dalam bekerja, sebab etika profesional merupakan pertimbangan etis dan pedoman profesional yang 
relevan pada setiap profesi (Rodríguez dan Juričić, 2018). Sehingga dapat dipahami bahwa setiap profesi tentu memiliki etika profesi yang berbeda dengan profesi yang lainnya. Namun demikian, ada beberapa etika profesional yang berlaku secara universal, seperti: tanggung jawab; integritas; objektivitas; dan menjaga kerahasiaan.

Jika menelisik dari paparan tersebut, maka peran menanamkan etika kepada seseorang sangat penting, agar ia mampu bekerja sama dengan orang lain secara tim dan diterima oleh komunitasnya. Apalagi kepada mahasiswa sebagai generasi muda juga sangat penting ditanamkan dalam dirinya tentang etika dan karakter. Pembentukan karakter pada diri mahasiswa menjadi hal yang krusial, mengingat setelah menempuh jenjang pendidikan di perguruan tinggi, ia akan memasuki dunia kerja. Karakter merupakan wujud dari perilaku yang dilakukan secara konsisten dan tidak berdiri sendiri, artinya karakter terintegrasi dengan sikap dan nilai yang diyakini oleh seseorang (Fahmy, dkk., 2015). Pembentukan karakter harus dilakukan selaras dengan pandangan hidup bangsa dan sikap hidup masyarakat yang merupakan hasil refleksi dari keragaman masyarakat (Ferdiawan, dkk., 2013). Seorang mahasiswa memiliki tanggung jawab moral mengembangkan nilai-nilai moral bangsa yang terwujud dalam perilakunya dengan berpedoman pada etika dan karakter bangsa.

\section{METODE}

Penelitian ini dilaksanakan dengan menggunakan pendekatan kuantitatif. Variabel yang diteliti adalah etika profesional $(\mathrm{X})$ sebagai variabel bebas dan pembentukan karakter mahasiswa (Y) sebagai variabel terikat. Instrumen untuk mengukur variabel penelitian ialah dengan angket. Bentuk angket yang digunakan adalah angket tertutup, yakni responden memberikan tanda silang pada pilihan jawaban yang dipilih pada angket penelitian. Teknik pengambilan sampel dengan menggunakan quota random sampling.

Sampel penelitian adalah mahasiswa yang mengikuti pelatihan Character Building dengan jumlah 73 orang mahasiswa dari populasi 260 orang mahasiswa Fakultas Ilmu Pendidikan (FIP) Universitas Negeri Malang (UM) yang mengikuti pelatihan Character Building. Pelatihan dilaksanakan pada hari Sabtu 4 November 2017 di Aula FIP UM. Analasis data yang digunakan adalah: analisis deskriptif dengan formula stanfive dan uji regresi sederhana. Analisis data dengan menggunakan IBM SPSS Statistics 20.

\section{HASIL}

\section{Deskripsi Data}

Variabel etika profesional $(\mathrm{X})$ diukur dengan menggunakan indikator: tanggung jawab profesi; kepentingan publik; integritas; objektivitas; kompetensi dan kehati-hatian profesional; kerahasiaan; perilaku profesional; dan standar teknis. Hasil analisis data terhadap variabel tersebut menunjukkan nilai: skor minimum 64; skor maksimum 91; rerata 80,26; dan deviasi standar 6,31. Selanjutnya data variabel etika profesional (X) dideskripsikan dengan rumus formula stanfive. Deskripsi frekuensi variabel etika profesional (X) seperti ditampilkan pada Tabel 1.

Tabel 1 Deskripsi Frekuensi Variabel Etika Profesional (X)

\begin{tabular}{ccccc}
\hline No & Interval & $\mathbf{F}$ & $\mathbf{\%}$ & Kategori \\
\hline 1 & $>89,73$ & 6 & 8,22 & Sangat baik \\
2 & $83,42-89,73$ & 16 & 21,92 & Baik \\
3 & $77,10-83,42$ & 21 & 28,77 & Cukup baik \\
4 & $70,79-77,10$ & 25 & 34,25 & Kurang baik \\
5 & $<70,79$ & 5 & 6,85 & Tidak baik \\
\hline & Jumlah & $\mathbf{7 3}$ & $\mathbf{1 0 0}$ & \\
\hline
\end{tabular}


Variabel pembentukan karakter (Y) diukur dengan menggunakan indikator: kata-kata pendukung; waktu berkualitas; hadiah; pelayanan; dan sentuhan fisik. Hasil analisis data terhadap variabel tersebut menunjukkan nilai: skor minimum 55; skor maksimum 93; rerata 77,3; dan deviasi standar 8,3. Selanjutnya data variabel pembentukan karakter (Y) dideskripsikan dengan rumus formula stanfive. Deskripsi frekuensi variabel pembentukan karakter (Y) seperti ditampilkan pada Tabel 2.

Tabel 2 Deskripsi Frekuensi Variabel Pembentukan Karakter (Y)

\begin{tabular}{ccccc}
\hline No & Interval & $\mathbf{F}$ & $\mathbf{\%}$ & Kategori \\
\hline 1 & $>89,75$ & 3 & 4,11 & Sangat baik \\
2 & $81,45-89,75$ & 24 & 32,88 & Baik \\
3 & $73,15-81,45$ & 23 & 31,51 & Cukup baik \\
4 & $64,85-73,15$ & 17 & 23,29 & Kurang baik \\
5 & $<64,85$ & 6 & 8,22 & Tidak baik \\
\hline & Jumlah & $\mathbf{7 3}$ & $\mathbf{1 0 0}$ & \\
\hline
\end{tabular}

\section{Analisis Regresi}

Analisis regresi parsial digunakan untuk menguji hipotesis: tidak ada pengaruh etika profesional (X) terhadap pembentukan karakter mahasiswa (Y). Formula yang digunakan untuk menghitung seberapa besar pengaruh etika profesional $(\mathrm{X})$ terhadap variabel pembentukan karakter mahasiswa (Y) adalah rumus uji t, dengan menggunakan taraf signifikansi 0,05 yakni $\mathrm{H} 0$ ditolak jika nilai signifikansi yang diperoleh sebesar $\leq 0,05$ dan $\mathrm{H} 0$ tak ditolak jika nilai signifikansi yang diperoleh sebesar $>0,05$ (Stevens, 1996; Gunawan, 2016a; Gunawan, 2013). Hasil analisis regresi variabel etika profesional (X) terhadap pembentukan karakter mahasiswa (Y) seperti pada Tabel 3. Berdasarkan Tabel 3 diketahui nilai signifikansi sebesar $0,000<0,05$ sehingga $\mathrm{H} 0$ ditolak, maka dapat disimpulkan ada pengaruh yang signifikan variabel etika profesional $(\mathrm{X})$ terhadap pembentukan karakter mahasiswa (Y). Koofisien regresi variabel etika profesional $(\mathrm{X})$ terhadap pembentukan karakter mahasiswa $(\mathrm{Y})$ adalah 0,310. Sumbangan efektif variabel etika profesional (X) terhadap pembentukan karakter mahasiswa (Y) adalah sebesar $9,6 \%$.

Tabel 3 Analisis Regresi Variabel Etika Profesional (X) terhadap Pembentukan Karakter (Y)

\begin{tabular}{cccccc}
\hline $\mathbf{R}$ & R Square & Sum of Squares & df & Mean Squares & t \\
\hline 0,310 & 0,096 & 477,183 & 1 & 63,129 & 3,733 \\
& & & 72 & & \\
\hline
\end{tabular}

Selanjutnya berdasarkan hasil analisis regresi secara parsial dihitung persamaan regresi dari tabel coefficients(a) seperti yang ditampilkan pada Tabel 4. Berdasarkan Tabel 4 dapat diketahui bahwa nilai konstanta $(\beta 0)$ sebesar 44,575; dan nilai koefisien variabel etika profesional $(\beta 1)$ sebesar 0,408 . Jadi persamaan regresinya adalah: $\hat{\mathrm{Y}}=44,575+0,408 \mathrm{X} 1$.

Tabel 4 Coefficients

\begin{tabular}{ccccccc}
\hline & & \multicolumn{2}{c}{ Unstandardized Coefficients } & Standardized Coefficients & & \\
\cline { 2 - 5 } & Model & $\mathbf{B}$ & Std. Error & Beta & t & Sig. \\
\hline 1 & (Constant) & 44.575 & 11.940 & & 3.733 & .000 \\
& $\mathrm{X}$ & .408 & .148 & .310 & 2.749 & .008 \\
\hline
\end{tabular}

a. Dependent Variable: Y

Konstanta sebesar 44,575 menyatakan bahwa jika tidak terdapat kenaikan skor dari etika profesional (X), maka skor pembentukan karakter mahasiswa (Y) adalah sebesar 44,575. Koefisien regresi sebesar 0,408 untuk variabel etika profesional $(\mathrm{X})$ menyatakan bahwa setiap penambahan satu skor etika profesional (X) akan memberikan kenaikan sebesar 0,408. 


\section{PEMBAHASAN}

Penelitian ini menyimpulkan terdapat pengaruh yang signifikan etika profesional terhadap pembentukan karakter mahasiswa. Berdasarkan simpulan penelitian dapat diketahui bahwa etika memiliki kedudukan yang penting dalam pembentukan karakter baik kepada mahasiswa. Hasil penelitian ini selaras dengan penelitian yang dilakukan oleh Cummings, dkk., (2018) yang menyimpulkan bahwa penilaian terhadap etika memiliki pengaruh yang signifikan terhadap profesionalisme dan karakter individu. Penanaman etika profesional dan karakter kepada mahasiswa harus terintegrasi dengan kegiatan perkuliahan yang dilakukan dosen (Jagger dan Volkman, 2014; Kalaitzidis dan Schmitz, 2012). Etika menjadi landasan berpijak bagi setiap orang untuk melakukan suatu pekerjaan.

Pemahaman mahasiswa terhadap prinsip-prinsip etika dan karakter akan mempengaruhi perilakunya ketika telah terjun dalam dunia kerja (Miloradova dan Ishkov, 2015; Winrow, 2016; Chang, 2011). Penanaman etika dan karakter merupakan hal yang serius harus dilaksanakan dalam pendidikan (Jagger dan Volkman, 2014; Church dan Ekberg, 2013; Hartini, dkk., 2012). Etika merupakan bagian yang tak terpisahkan dalam pendidikan karakter (Gunawan, 2017; Kusumaningrum, dkk., 2017; Kusmintardjo dan Gunawan, 2017). Etika profesional akan terus mengalami dinamika, sesuai dengan tuntutan dan perkembangan pada jamannya. Nilai-nilai moral yang diyakini oleh suatu masyarakat akan menentukan etika dan karakter yang dimiliki oleh seseorang. Nilai-nilai positif akan menjadi sumber dalam pengembangan etika profesional.

Oleh sebab itu, setiap perbuatan yang dianggap bermoral (beretika) atau mempunyai nilai etik, jika memenuhi tolak ukur, maka akan menjadi etika yang diakui oleh masyarakat (Gunawan, 2016b). Karakter sebagai manifestasi etika pada gilirannya harus diarahkan pada pembinaan dan pengembangan moral setiap individu sebagai bagian dari masyarakat, bangsa, dan negara. Upaya membumikan etika dalam rangka menanamkan karakter baik perlu dilakukan secara massif, terutama pada diri mahasiswa yang merupakan generasi penerus bangsa. Perguruan tinggi sebagai lembaga pendidikan yang memiliki marwah intelektual bertanggung jawab terhadap penanaman etika dan karakter yang baik kepada para mahasiswanya. Etika tersebut bersumber dari nilai-nilai agama, kebudayaan bangsa Indonesia, dan harus tanggap terhadap tuntutan perubahan jaman.

Mahasiswa yang dalam berperilaku berpedoman teguh pada etika merupakan mahasiswa yang memiliki karakter baik. Etika yang diyakininya menjadi acuan dalam berinteraksi dengan semua orang. Etika profesional sebagai bekal mahasiswa memasuki dunia kerja juga harus menjadi bagian integral dalam diri mahasiswa yang berkarakter. Pembentukan karakter mahasiswa yang dilandasi dengan etika akan bertahan lebih lama dalam diri mahasiswa, sebab etika dan karakter yang ditampilkan telah terinternalisasi dalam diri mahasiswa.

\section{KESIMPULAN DAN SARAN}

\section{Kesimpulan}

Berdasarkan hasil analisis data penelitian disimpulkan bahwa terdapat pengaruh yang signifikan variabel etika profesional $(\mathrm{X})$ terhadap pembentukan karakter mahasiswa $(\mathrm{Y})$. Koofisien regresi variabel etika profesional $(\mathrm{X})$ terhadap pembentukan karakter mahasiswa $(\mathrm{Y})$ adalah 0,310. Sumbangan efektif variabel etika profesional $(\mathrm{X})$ terhadap pembentukan karakter mahasiswa $(\mathrm{Y})$ adalah sebesar 9,6\%. Hasil penelitian ini berarti mendukung teori yang menyatakan bahwa etika profesional memiliki pengaruh yang signifikan terhadap pembentukan karakter.

\section{DAFTAR RUJUKAN}

Chan, J. K. H. 2018. Design Ethics: Reflecting on the Ethical Dimensions of Technology, Sustainability, and Responsibility in the Anthropocene. Design Studies, 54, 184-200.

Chang, C. L. 2011. The Effect of an Information Ethics Course on the Information Ethics Values of Students - A Chinese Guanxi Culture Perspective. Computers in Human Behavior, 27(5), 2028-2038. 
Church, S., dan Ekberg, M. 2013. Student Midwives' Responses to Reproductive Ethics: A Qualitative Focus Group Approach Using Case Scenarios. Midwifery, 29(8), 895-901.

Cummings, C. L., Geis, G. M., Feldman, H. A., Berson, E. R., dan Kesselheim, J. C. 2018. Assessing Ethics Knowledge: Development of a Test of Ethics Knowledge in Neonatology. The Journal of Pediatrics, 196, 335-342.

Fahmy, R., Bachtiar, N., Rahim, R., dan Malik, M. 2015. Measuring Student Perceptions to Personal Characters Building in Education: An Indonesian Case in Implementing New Curriculum in High School. Procedia Social and Behavioral Sciences, 211, 851-858.

Ferdiawan, E., dan Putra, W. A. 2013. ESQ Education for Children Character Building based on Phylosophy of Javaness in Indonesia. Procedia - Social and Behavioral Sciences, 106, 1096-1102.

Greenstone, A. F. 2018. Ethics and Public Integrity in Space Exploration. Acta Astronautica, 143, 322-326.

Gunawan, I. 2013. Statistika untuk Kependidikan Sekolah Dasar. Yogyakarta: Penerbit Ombak.

Gunawan, I. 2015. Mengembangkan Kepemimpinan Kepala Sekolah Berbasis Nilai dan Etika. Proceeding National Seminar and International Conference Scientific Forum-Faculty of Education Department of Science Educatioin (FIP-JIP), Fakultas Ilmu Pendidikan Universitas Negeri Gorontalo, Gorontalo, 9 s.d. 11 September, hlm. 302-312.

Gunawan, I. 2016a. Pengantar Statistika Inferensial. Jakarta: Rajawali Pers.

Gunawan, I. 2016b. Perspectives of Pancasila: Leadership Education's Values and Ethics. Proceeding International Conferences on Education and Training, 2nd ICET Theme: Improving the Quality of Education and Training Through Strengthening Networking, Fakultas Ilmu Pendidikan Universitas Negeri Malang, Malang, hlm. 435-438.

Gunawan, I. 2017. Landasan Dasar Pendidikan. Malang: Universitas Negeri Malang, Penerbit UM Press.

Hartini, Gunawan, I., dan Suraya, S. N. 2012. Persepsi Mahasiswa terhadap Kualitas Pelayanan Pendidikan FIP IKIP PGRI MADIUN. Jurnal Pendidikan, 18(1), 37-66.

Jagger, S., dan Volkman, R. 2014. Helping Students to See for Themselves that Ethics Matters. The International Journal of Management Education, 12(2), 177-185.

Kalaitzidis, E., dan Schmitz, K. 2012. A Study of An Ethics Education Topic for Undergraduate Nursing Students. Nurse Education Today, 32(1), 111-115.

Kusmintardjo, dan Gunawan, I. 2017. Manajemen Layanan Khusus. Malang: Universitas Negeri Malang, Penerbit UM Press.

Kusumaningrum, D. E., Benty, D. D. N., dan Gunawan, I. 2017. Manajemen Peserta Didik. Malang: Universitas Negeri Malang, Penerbit UM Press.

Miles, S. H., dan Craddock, S. 2018. Ethics for the Anthropocene Epoch. Encyclopedia of the Anthropocene, 4, 21-27.

Miloradova, N., dan Ishkov, A. 2015. Environmental Ethics as a Social, Professional and Personal Value of the Students of Civil Engineering University. Procedia Engineering, 117, 246-251.

Pertiwi, A. K., Cahyani, S. S. A., Diana, R. C., dan Gunawan, I. 2017. Kepemimpinan Berbasis Nilai dan Etika: Suatu Kajian Interaksi Simbolik Kyai dan Santri. Prosiding Seminar Nasional Pendidikan: Sinergitas Keluarga, Sekolah, dan Masyarakat dalam Penguatan Pendidikan Karakter, Universitas Negeri Malang, Malang, 16 Novemver, hlm. 1-9.

Rodríguez, J. V., dan Juričić, Z. 2018. Perceptions and Attitudes of Community Pharmacists toward Professional Ethics and Ethical Dilemmas in the Workplace. Research in Social and Administrative Pharmacy, 14(5), 441450.

Stevens, J. 1996. Applied Multivariate Statistics for the Social Sciences. Mahwah: Lawrence Erlbaum Associates.

Winrow, B. 2016. Do Perceptions of the Utility of Ethics Affect Academic Cheating? Journal of Accounting Education, 37, 1-12. 